\title{
AN EFFICIENT AND GREEN PROTOCOL FOR THE SYNTHESIS OF DIHYDROPYRANO [2,3-C] PYRAZOLES IN AQUEOUS MEDIUM USING THIAMINE HYDROCHLORIDE AS A CATALYST
}

\author{
MUKESH D. NIKAM, PRAVIN S. MAHAJAN, ASHA V. CHATE, SANJAY K. DABHADE, \\ CHARANSINGH H. GILL*
}

Department of Chemistry, Dr. Babasaheb Ambedkar Marathwada University, Aurangabad, Maharashtra, 431004, India.

\section{ABSTRACT}

A green and expedient approach for the synthesis of dihydropyrano[2,3-c] pyrazoles via four-component reaction of ethyl acetoacetate, hydrazine hydrate, aromatic aldehydes and malononitrile at room temperature under ultrasound irradiation is described. The reaction has been catalyzed by thiamine hydrochloride in aqueous medium. This protocol afforded several advantages such as inexpensive, easily available catalyst, simple operational procedure, excellent yield, use of aqueous medium and ultrasound irradiation that is considered to be relatively eco-friendly.

Keywords: Multicomponent reaction, Dihydropyrano[2,3-c]pyrazoles, Green chemistry, Aqueous medium, Ultrasound irradiation.

\section{INTRODUCTION}

Multicomponent reactions (MCRs) are known as a powerful synthetic strategy in recent years for the construction of novel and structurally complex molecules in a one pot ensuring high atom-economy, high selectivity, energy saving, shorter reaction times and avoidance of expensive purification processes. ${ }^{1}$ MCRs, particularly those performed in aqueous media, have become increasingly useful tools for the synthesis of chemically and biologically important compounds because of their ecologically aware and green characteristics. ${ }^{2}$ Water is the safest and most abundant substance in nature. ${ }^{3}$ Hence it is referred to as a benign 'Universal Solvent'. ${ }^{4}$ Because of these advantages, the design of new MCRs with environmentally benign method is a continuing challenge at the forefront area of green chemistry.

Dihydropyrano[2,3-c]pyrazoles scaffold plays an important role in biologically active compounds and therefore represents an interesting template for medicinal chemistry. The pyranopyrazoles have been reported to exhibit interesting biological properties such as antimicrobial, ${ }^{5}$ analgesic, ${ }^{6}$ antiinflammatory, ${ }^{7}$ insecticidal ${ }^{8}$ and molluscicidal ${ }^{9}$ and also serve as potential inhibitors of human Chk1 kinase. ${ }^{10}$ As consequence, synthesis of these important pharmacophore attracted more attention of pharmaceutical industry and organic chemists.

There are several methods reported for the preparation of various classes of dihydropyrano [2,3-c]pyrazole derivatives, most of which have been carried out in the presence of base catalysts. ${ }^{11-15}$ Although, the reported methods are effective, they have limited applicability by the use of toxic catalysts, long reaction times, low yields of products and the use of toxic organic solvents. Recently, some environment-compatible catalysts such as L-proline, ${ }^{16}$ $\gamma$-alumina, ${ }^{17}$ per-6-amino- $\beta$-cyclodextrin ${ }^{18}$ and imidazole ${ }^{19}$ were also used to achieve this transformation, but mostly at elevated temperature. Inspite of many reported methods for the synthesis of dihydropyrano[2,3-c]pyrazole derivatives, the development of a new synthetic strategy using easily accessible catalyst and mild reaction condition still demand a lot of attention.

From the ecofriendly point of view combining with economic aspects "Green chemistry" emphasizes the development of metal ion free, environmentally safe and convenient reagents in the MCRs ${ }^{20}$. In this regard, thiamine hydrochloride $\left(\mathrm{VB}_{;} ;\right.$Fig. 1) have been used as versatile catalyst which has reflected their applications in various organic transformations for carbon-carbon and carbon-hetero atom bond formation reactions ${ }^{21}$. VB as a green catalyst has created enormous interest in researchers ${ }^{22}$ because of its non toxicity, low cost, ease of handling, water and air compatibility.

Nowadays, the application of ultrasound in organic synthesis has been increasing because of its advantages such as shorter reaction times, milder reaction conditions and higher yields in comparison with the classical methods. ${ }^{23}$ The chemical and physical effects of ultrasound arise from the cavitational collapse which produces extreme conditions locally and thus induce the formation of chemical species not easily attained under conventional conditions ${ }^{24}$.

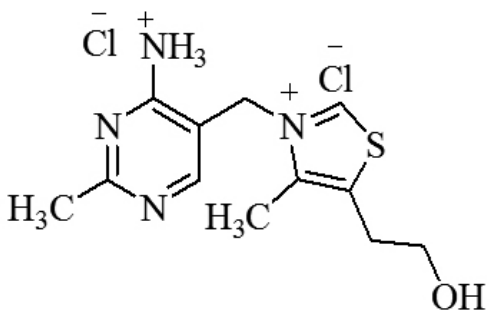

Figure 1 The structure of thiamine hydrochloride $\left(\mathrm{VB}_{1}\right)$.

In continuation of our endeavor toward the development of ecofriendly synthetic protocols ${ }^{25}$ and $\mathrm{VB}_{1}$ catalysed reactions ${ }^{26}$. Herein, we wish to report a one-pot multicomponent synthesis of dihydropyrano[2,3-c]pyrazoles by the reaction of ethyl acetoacetate, hydrazine hydrate, aryl/heteroaryl aldehydes, and malononitrile using thiamine hydrochloride in aqueous medium by conventional and non-conventional method (Scheme 1).

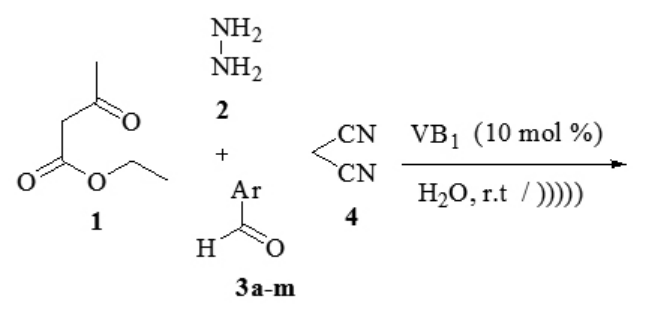

Scheme 1

\section{EXPERIMENTAL}

All reagents and chemicals were of analytical grade and used without further purification. Melting points were recorded by open tube capillary method and are uncorrected. IR spectrum of all compounds was recorded with FT-IR spectrophotometer (Brucker). ${ }^{1} \mathrm{HNMR}$ (Varian NMR $400 \mathrm{~Hz}$ ) of compounds $5 \mathrm{a}-\mathrm{m}$ was recorded in $\mathrm{CDCl}_{3}$ using TMS as an internal standard and molecular weight was confirmed by using LC-MS

General procedure for synthesis of $\mathbf{5 a - m}$

Conventional method: A mixture of ethyl acetoacetate (1 mmol), hydrazine hydrate $(1 \mathrm{mmol})$, aromatic aldehyde $(1 \mathrm{mmol})$, malononitrile $(1 \mathrm{mmol})$ and thiamine hydrochloride $(10 \mathrm{~mol} \%)$ in water $(5 \mathrm{~mL})$ was taken in a $50 \mathrm{ml}$ roundbottomed flask. The resulting mixture was stirred at room temperature for a 
period as indicated in Table 4. After completion of the reaction (monitored by TLC), the solid obtained was collected by simple filtration and washed successively with water. The crude product was purified by crystallization from ethanol to afford the desired product. The products $(\mathbf{5 a}-\mathbf{m})$ were confirmed by comparing the physical and spectral data with those of the reported compounds.

Ultrasound method: A mixture of ethyl acetoacetate $(1 \mathrm{mmol})$, hydrazine hydrate $(1 \mathrm{mmol})$, aromatic aldehyde $(1 \mathrm{mmol})$, malononitrile $(1 \mathrm{mmol})$ and thiamine hydrochloride $(10 \mathrm{~mol} \%)$ in water $(5 \mathrm{~mL})$ was taken in a $50 \mathrm{ml}$ roundbottomed flask. The mixture was irradiated in the water bath of an ultrasonic cleaner at $25-30{ }^{\circ} \mathrm{C}$ for a period as indicated in Table 4 . After completion of the reaction (monitored by TLC), the solid obtained was collected by simple filtration and washed successively with water. The crude product was purified by crystallization from ethanol to afford the desired product. The products $(\mathbf{5 a}-$ m) were confirmed by comparing the physical and spectral data with those of the reported compounds ${ }^{12,17}$.

Spectra data of the representative compounds:

(5a)Yellow solid, IR (KBr): 3455, 3320, 2225, 1661, $1587 \mathrm{~cm}^{-1} ;{ }^{1} \mathrm{H}$ NMR $\left(400 \mathrm{MHz}, \mathrm{CDCl}_{3}\right) 1.89$ (s, $\left.3 \mathrm{H}, \mathrm{CH}_{3}\right) ; 4.86(\mathrm{~s}, 1 \mathrm{H}, \mathrm{CH}) ; 6.79$ (s, br, $\left.2 \mathrm{H}, \mathrm{NH}_{2}\right)$; 7.10-7.65 (m, 5H, $J=7.5-8 \mathrm{~Hz}, \mathrm{Ar}-\mathrm{H}) ; 12.35(\mathrm{~s}, 1 \mathrm{H}, \mathrm{NH}) ; \mathrm{ES}-\mathrm{MS} \mathrm{m} / \mathrm{z}: 253$ $(\mathrm{M}+\mathrm{H}) .(5 \mathrm{~b})$ White solid, IR (KBr): 3430, 3025, 2975, 1627, $1575 \mathrm{~cm}^{-1} ;{ }^{1} \mathrm{H}$ NMR (400 MHz, $\left.\mathrm{CDCl}_{3}\right) 1.90\left(\mathrm{~s}, 3 \mathrm{H}, \mathrm{CH}_{3}\right) ; 5.20(\mathrm{~s}, 1 \mathrm{H}, \mathrm{CH}) ; 6.91(\mathrm{~s}, \mathrm{br}, 2 \mathrm{H}$, $\left.\mathrm{NH}_{2}\right) ; 7.15-7.70(\mathrm{~m}, 4 \mathrm{H}, J=7.3-7.9 \mathrm{~Hz}, \mathrm{Ar}-\mathrm{H}) ; 12.40$ (s, $\left.1 \mathrm{H}, \mathrm{NH}\right) ; \mathrm{ES}-\mathrm{MS} \mathrm{m} / \mathrm{z}$ $287(\mathrm{M}+\mathrm{H}) .(\mathbf{5 d})$ Yellowish solid; IR (KBr): $3475,3186,2190,1651 \mathrm{~cm}^{-1} ;{ }^{1} \mathrm{H}$ NMR (400 MHz, CDCl $): 1.97\left(\mathrm{~s}, 3 \mathrm{H}, \mathrm{CH}_{3}\right), 4.77(\mathrm{~s}, 1 \mathrm{H}, \mathrm{CH}), 6.21(\mathrm{~s}, 2 \mathrm{H}$, $\left.\mathrm{NH}_{2}\right), 7.53(\mathrm{~d}, 2 \mathrm{H}, J=7.6 \mathrm{~Hz}, \mathrm{Ar}-\mathrm{H}), 8.04$ (d,2H, $\left.J=8 \mathrm{~Hz}, \mathrm{Ar}-\mathrm{H}\right), 12.06$ (s, $1 \mathrm{H}, \mathrm{NH})$; ES-MS m/z: $298(\mathrm{M}+\mathrm{H})$. (5e) white solid, IR (KBr): 3390, 3239, 3145, 2971, 2195, 1644, $1603 \mathrm{~cm}^{-1} ;{ }^{1} \mathrm{H}$ NMR $\left(400 \mathrm{MHz}, \mathrm{CDCl}_{3}\right): 1.81(\mathrm{~s}, 3 \mathrm{H}$, $\left.\mathrm{CH}_{3}\right), 4.49(\mathrm{~s}, 1 \mathrm{H}, \mathrm{CH}), 6.71(\mathrm{~d}, J=8.4 \mathrm{~Hz}, 2 \mathrm{H}, \mathrm{Ar}-\mathrm{H}), 6.76\left(\mathrm{~s}, 2 \mathrm{H}, \mathrm{NH}_{2}\right), 6.93$ (d, $J=8.4 \mathrm{~Hz}, 2 \mathrm{H}, \mathrm{Ar}-\mathrm{H}), 9.27$ (s, 1H, OH), 12.01 (s, 1H, NH); ES-MS m/z: $269(\mathrm{M}+\mathrm{H}) .(\mathbf{5 h})$ White solid, IR (KBr): 3370, 3050, 2785, $1600 \mathrm{~cm}^{-1} ;{ }^{1} \mathrm{H}$ NMR $\left(400 \mathrm{MHz}, \mathrm{CDCl}_{3}\right): 1.85\left(\mathrm{~s}, 3 \mathrm{H}, \mathrm{CH}_{3}\right), 2.21\left(\mathrm{~s}, 3 \mathrm{H}, \mathrm{CH}_{3}\right), 4.52(\mathrm{~s}, 1 \mathrm{H}, \mathrm{CH}), 6.72$ (s, 2H, NH $)_{2}, 7.04-7.13(\mathrm{~m}, 4 \mathrm{H}, \mathrm{Ar}-\mathrm{H}), 12.10(\mathrm{~s}, 1 \mathrm{H})$; ES-MS m/z: $267(\mathrm{M}+\mathrm{H})$ (5i) white solid IR (KBr): 3390, 3240, 3180, 2921, 2175, 1643, $1589 \mathrm{~cm}^{-1}$; ${ }^{1} \mathrm{HNMR}\left(400 \mathrm{MHz}, \mathrm{CDCl}_{3}\right): 1.79\left(\mathrm{~s}, 3 \mathrm{H}, \mathrm{CH}_{3}\right), 4.65(\mathrm{~s}, 1 \mathrm{H}, \mathrm{CH}), 6.87(\mathrm{~s}, 2 \mathrm{H}$, $\left.\mathrm{NH}_{2}\right), 7.19$ (d, $\left.J=8.2 \mathrm{~Hz}, 2 \mathrm{H}, \mathrm{Ar}-\mathrm{H}\right), 7.55(\mathrm{~d}, J=8.1 \mathrm{~Hz}, 2 \mathrm{H}, \mathrm{Ar}-\mathrm{H}), 12.14$ (s, 1H, NH); ES-MS m/z: $331(\mathrm{M}+\mathrm{H})$.

\section{RESULTS AND DISCUSSION}

In order to optimize the reaction conditions, initially we carried out the reaction between ethyl acetoacetate $\mathbf{1}(1 \mathrm{mmol})$, hydrazine hydrate 2 (1 mmol), benzaldehyde $\mathbf{3 a}(1 \mathrm{mmol})$ and malononitrile $4(1 \mathrm{mmol})$ as a model reaction. In the beginning, the model reaction was carried out in the absence of catalyst, it was found that only a low yield of product was obtained even after 60 min (Table 1, entry 1). Therefore to improve the yield, it was thought that intervention of catalyst is necessary. Hence, we tried a various catalysts like $\mathrm{K}_{2} \mathrm{CO}_{3}$, imidazole, $\mathrm{Al}_{2} \mathrm{O}_{3}$, L-proline and thiammine hydrochloride $\left(\mathrm{VB}_{1}\right)$ to promote this transformation at room temperature. To our delight, reaction proceeds smoothly in the presence of $\mathrm{VB}_{1}$ affording higher yield (91\%) within 15 min. (Table 1, entry 6) Therefore, considering the effective catalytic activity, $\mathrm{VB}_{1}$ was preferred as a catalyst of choice for subsequent optimization studies.

Table.1: Screening of the catalytic activities of various catalyst ${ }^{\mathrm{a}}$

\begin{tabular}{|c|c|c|c|}
\hline Entry & Catalyst & Time (min) & Yield $^{\mathrm{b}}(\%)$ \\
\hline 1 & No catalyst & 60 & 7 \\
\hline 2 & $\mathrm{~K}_{2} \mathrm{CO}_{3}$ & 60 & 36 \\
\hline 3 & Imidazole & 60 & 68 \\
\hline 4 & $\mathrm{Al}_{2} \mathrm{O}_{3}$ & 75 & 20 \\
\hline 5 & $\mathrm{~L}-p r o l i n e$ & 60 & 52 \\
\hline 6 & $\mathrm{VB}_{1}$ & 15 & 91 \\
\hline
\end{tabular}

aReaction conditions: ethyl acetoacetate $(1 \mathrm{mmol})$, hydrazine hydrate $(1$ $\mathrm{mmol})$, benzaldehyde $(1 \mathrm{mmol})$, malononitrile $(1 \mathrm{mmol})$ and catalyst $(10 \mathrm{~mol}$ $\%)$, in water $(5 \mathrm{~mL})$ at r.t.

${ }^{\mathrm{b}}$ Isolated yield.

Encouraged by these results we further investigated the influence of catalyst concentration on the reaction time and percentage yield. We performed the reaction using different molar concentrations of catalyst, it is found that when the catalyst concentration was $2.5 \mathrm{~mol} \%$, the yield was found to be $67 \%$ within 50 min (Table 2, entry 1), but when the catalyst concentration was increased to $10 \mathrm{~mol} \%$, the yield was found to be $91 \%$ within $15 \mathrm{~min}$ (Table 2, entry 4). Further increase in the concentration of catalyst did not improve the yields. It was therefore concluded that the optimum concentration of catalyst was $10 \mathrm{~mol} \%$.

Table 2: Effect of catalyst concentration on model reaction ${ }^{\mathrm{a}}$

\begin{tabular}{|c|c|c|c|}
\hline Entry & Catalyst $(\mathrm{mol} \%)$ & Time $(\mathrm{min})$ & Yield $^{\mathrm{b}}(\%)$ \\
\hline 1 & 2.5 & 50 & 67 \\
\hline 2 & 5 & 30 & 79 \\
\hline 3 & 7.5 & 15 & 86 \\
\hline 4 & 10 & 15 & 91 \\
\hline 5 & 12.5 & 15 & 91 \\
\hline
\end{tabular}

a Reaction conditions: ethyl acetoacetate $(1 \mathrm{mmol})$, hydrazine hydrate (1 mmol), benzaldehyde $(1 \mathrm{mmol})$, malononitrile $(1 \mathrm{mmol})$ and thiamine hydrochloride in water $(5 \mathrm{~mL})$ at r.t.

${ }^{\mathrm{b}}$ Isolated yield.

To compare the efficiency of the solvent, various solvents were screened. The results indicate that solvents affected the efficiency of the catalyst (Table 3, entries 1-7). When the reaction was performed under solvent-free conditions, the yield was very low $(40 \%)$. To our surprise in case of protic solvent such as $\mathrm{EtOH}$, water and water:ethanol (1:1) the reaction rate as well as the product yields were found to be improved comparatively (Table 3, entries 5-7).

After screening of different solvents, water was found to be the medium of choice, which afforded the highest yield (Table 3, entry 6).

Table 3: Optimization of solvent effect on the model reaction ${ }^{\mathrm{a}}$

\begin{tabular}{|c|c|c|c|}
\hline Entry & Solvent & Time (min) & Yield $^{\mathrm{b}}(\%)$ \\
\hline 1 & No solvent & 120 & 40 \\
\hline 2 & MeCN & 90 & 60 \\
\hline 3 & THF & 60 & 67 \\
\hline 4 & DCM & 90 & 56 \\
\hline 5 & EtOH & 35 & 84 \\
\hline 6 & $\mathrm{H}_{2} \mathrm{O}$ & 15 & 91 \\
\hline 7 & $\mathrm{H}_{2} \mathrm{O}: \mathrm{EtOH}(1: 1)$ & 20 & 88 \\
\hline
\end{tabular}

a Reaction conditions: ethyl acetoacetate $(1 \mathrm{mmol})$, hydrazine hydrate (1 mmol), benzaldehyde ( $1 \mathrm{mmol})$, malononitrile $(1 \mathrm{mmol})$, thiamine hydrochloride $(10 \mathrm{~mol} \%)$ in solvent $(5 \mathrm{~mL})$ at r.t.

${ }^{\mathrm{b}}$ Isolated yield.

Considering the well recognized applications of ultrasound to promote variety of chemical reactions, we next attempted to carry out the model reaction using optimized reaction conditions under ultrasound irradiation at $25-30{ }^{\circ} \mathrm{C}$ to check whether, the reaction could be accelerated and the product yield could be further improved. Assistance of ultrasound irradiation resulted into the slight improvement in the product yield (93\%).It is worth noting here, that the reaction time is reduced significantly as compared to the conventional method. The difference in the reaction times is due to the specific effects of ultrasound. The effect observed on the reaction is due to the phenomenon of acoustic cavitation. The collapse of cavitation bubbles result in the formation of very reactive chemical species having short lifetime which facilitates the rapid synthesis of dihydropyrano [2, 3-c]pyrazole derivatives. Increasing temperature under ultrasonic conditions enhances the conversion rate, but diminishes the desired product yield. Schematic representation depicting possible mechanism for $\mathrm{VB}_{1}$ catalyzed synthesis of dihydropyrano[2,3-c] pyrazoles is rationalized in scheme 2 .

Having established optimum experimental conditions in hand, next we examined the scope and generality of this method using a variety of substituted aromatic aldehydes for synthesizing dihydropyrano[2,3-c]pyrazoles under conventional and ultrasound method. Under the optimized conditions, 
irrespective of the substituent present on the aromatic ring of the aldehyde, the corresponding products were obtained in high to excellent yields (Table 4).More importantly, hetero aryl aldehydes were observed to be well tolerated under optimized conditions furnishing the product in good yields. Formation of the desired product was confirmed by comparing their physical constants, IR, ${ }^{1} \mathrm{H}$ NMR and mass spectroscopic data with those of reported compounds.<smiles>[CH]c1sc(CCO)c(C)[n+]1[C-]c1cnc(C)nc1[N]</smiles><smiles>CCOC(=O)C(CCN)(CCN)OC1CCCCCC1</smiles>

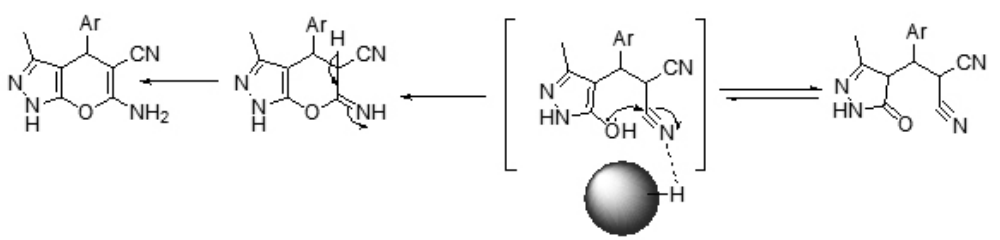

Scheme 2.Proposed mechanism for the synthesis of dihydropyrano[2,3-c]pyrazole derivatives.

Table 4: Synthesis of dihydropyrano [2,3-c]pyrazole derivatives (5a-m)

\begin{tabular}{|c|c|c|c|c|c|c|c|}
\hline \multirow{2}{*}{ Entry } & \multirow{2}{*}{ Compound } & \multirow{2}{*}{$\mathrm{Ar}$} & \multicolumn{2}{|c|}{ Conventional $^{\mathrm{a}}$} & \multicolumn{2}{|c|}{ Ultrasound irradiation ${ }^{\mathrm{b}}$} & \multirow{2}{*}{ Melting point } \\
\hline & & & Time (min) & Yield $^{c}(\%)$ & Time (min) & Yield $^{c}(\%)$ & \\
\hline 1 & $5 a$ & $-\mathrm{C}_{6} \mathrm{H}_{5}$ & 15 & 91 & 8 & 93 & $241-243^{17}$ \\
\hline 2 & $5 \mathbf{b}$ & $4-\mathrm{ClC}_{6} \mathrm{H}_{4}$ & 15 & 92 & 9 & 94 & $231-233^{17}$ \\
\hline 3 & $5 c$ & $3-\mathrm{NO}_{2} \mathrm{C}_{6} \mathrm{H}_{4}$ & 17 & 91 & 7 & 93 & $192-195^{17}$ \\
\hline 4 & $5 d$ & $4-\mathrm{NO}_{2} \mathrm{C}_{6} \mathrm{H}_{4}$ & 15 & 90 & 6 & 94 & $250-252^{17}$ \\
\hline 5 & $5 e$ & $4-\mathrm{OHC}_{6} \mathrm{H}_{4}$ & 15 & 93 & 11 & 93 & $221-224^{17}$ \\
\hline 6 & $5 f$ & $2-\mathrm{ClC}_{6} \mathrm{H}_{4}$ & 16 & 90 & 9 & 92 & $141-144^{17}$ \\
\hline 7 & $5 \mathrm{~g}$ & $4-\mathrm{OCH}_{3} \mathrm{C}_{6} \mathrm{H}_{4}$ & 15 & 89 & 10 & 91 & $207-210^{17}$ \\
\hline 8 & $5 \mathrm{~h}$ & $4-\mathrm{CH}_{3} \mathrm{C}_{6} \mathrm{H}_{4}$ & 10 & 93 & 9 & 93 & $207-210^{17}$ \\
\hline 9 & $5 i$ & 4- $\mathrm{BrC}_{6} \mathrm{H}_{4}$ & 17 & 89 & 7 & 91 & $175-177^{17}$ \\
\hline 10 & $5 \mathbf{j}$ & $4-\mathrm{HO}-3 \mathrm{OMeC}_{6} \mathrm{H}_{3}$ & 18 & 93 & 10 & 93 & $235-238^{17}$ \\
\hline 11 & $5 \mathbf{k}$ & $4-\mathrm{N}\left(\mathrm{CH}_{3}\right)_{2} \mathrm{C}_{6} \mathrm{H}_{4}$ & 16 & 90 & 9 & 90 & $165-168^{17}$ \\
\hline 12 & 51 & 2-Furyl & 20 & 88 & 10 & 89 & $235-238^{12}$ \\
\hline 13 & $5 \mathrm{~m}$ & 2-Thienyl & 20 & 86 & 11 & 90 & $234-237^{12}$ \\
\hline
\end{tabular}

${ }^{a}$ Reaction conditions: ethyl acetoacetate $(1 \mathrm{mmol})$, hydrazine hydrate $(1 \mathrm{mmol})$, aryl aldehyde $(1 \mathrm{mmol})$, malononitrile $(1 \mathrm{mmol})$ and thiamine hydrochloride $(10 \mathrm{~mol} \%)$ in water $(5 \mathrm{~mL})$ at r.t.

${ }^{b}$ Reaction conditions: ethyl acetoacetate $(1 \mathrm{mmol})$, hydrazine hydrate $(1 \mathrm{mmol})$, aryl aldehyde $(1 \mathrm{mmol})$, malononitrile $(1 \mathrm{mmol})$ and thiamine hydrochloride $(10 \mathrm{~mol} \%)$ in water $(5 \mathrm{~mL})$ under ultrasound irradiation.

${ }^{\mathrm{c}}$ Isolated yield.

${ }^{\mathrm{d}}$ Literature references.

\section{CONCLUSION}

In conclusion, we have achieved the synthesis of dihydropyrano[2,3-c] pyrazole derivatives in excellent yields by a simple and efficient procedure in aqueous conditions under ultrasound irradiation and in the presence of thiamine hydrochloride as catalyst. The important features of this protocol are the very short reaction time, high yields, simple workup, and non-chromatographic purification of products. The present method involves use of water as solvent and a non conventional energy source. Therefore, this procedure could be classified within green chemistry. 


\section{ACKNOWLEDGEMENTS}

The authors are grateful to the Head, Department of Chemistry, Dr. Babasaheb Ambedkar Marathwada University, Aurangabad for providing the laboratory facility and MDN thanks Council of Scientific and Industrial Research, New Delhi for providing Senior Research Fellowship.

\section{REFERENCES}

1. (a) B.M. Trost, Angew. Chem. Int. Ed. Engl. 34, 259, (1995). (b) P.A. Wender, S.T. Hanhdy, D.L. Wright, Chem. Ind. 765, 767, (1997). (c) L. Weber, Curr. Opin. Chem. Biol. 4, 295, (2000). (d) A. Dömling, Curr. Opin. Chem. Biol. 6, 306, (2002).

2. (a) K. Kumaravel, G. Vasuki, Green Chem.11, 1945, (2009). (b) G. W Wang, C. B. Miao, Green Chem. 8, 1080, (2006).(c) S. L. Jain, S. Singhal, B. Sain, Green Chem. 9, 740, (2007). (d) G. Zhao, T. Jiang, H. Gao, B. Han, J. Huang, D. Sun, Green Chem. 6, 75, (2004). (e) A. Domling, Chem. Rev. 17, 106, (2006). (f) A. Shaabani, E. Soleimani, H. R. Khavasi, TetrahedronLett. 47, 4743 (2007). (g) Y. Gu, R. DeSousa, G. Frapper, C. Bachmann, J. Barrault, F. Jerome, Green Chem. 11,1968, (2009).

3. E. S. Beach, Z. Cui, P. T. Anastas, Energy Environ. Sci.2, 1038, (2009).

4. (a) R. Breslow, Green Chem. 5, 225, (1998).(b) C.J. Li, L. Chen, Chem. Soc. Rev. 35, 68, (2006). (c) C.J. Li, Chem. Rev. 105, 3095, (2005).

5. E. S. El-Tamany, F. A. El-Shahed, B. H. Mohamed, J. Serb. Chem. Soc. 64, 9, (1999).

6. S. C. Kuo, L. J. Huang, H. Nakamura, J. Med. Chem. 27, 539, (1984).

7. M. E. A. Zaki, H. A. Soliman, O. A. Hiekal, A. E. Z. Rashad, Naturforsch. C61, 1, (2006).

8. (a) F. M. Abdelrazek, P. Metz, N. H. Metwally, S. F. El-Mahrouky, Arch Pharm. 339, 456, (2006).(b) F.M. Abdelrazek, P. Metz, O. Kataeva, A. Jaeger, S.F. El- Mahrouky, Arch. Pharm. 340, 543, (2007).

9. Z. H. Ismail, G. M. Aly, M. S. El-Degwi, H. I. Heiba, M. M. Ghorab, Egyp. J. Biotechnol. 13, 73, (2003).

10. N. Foloppe, L. M. Fisher, R. Howes, A. Potter, A. G. S. Robertson, A.E. Surgenor, Bioorg. Med. Chem. 14, 4792, (2006).

11. G. Vasuki, K. Kumaravel, Tetrahedron Lett. 49, 5636, (2008).

12. Y.M. Litvinov, A.A. Shestopalov, L. A. Rodinovskaya, A.M. Shestopalov, J. Comb. Chem.11, 914, (2009).

13. Y. Peng, G. Song, R.Dou, Green Chem. 8, 573, (2006).

14. F. Lehman, M. Holm, S.Laufer, J. Comb. Chem.10, 364, (2008).

15. H.M. Al-Matar, K.D. Khalil, A.Y. Adam, M.H. Elnagdi, Molecules15, $6619,(2010)$.

16. H. Mecadon, M.R. Rohman, I.Kharbangar, B.M. Laloo, I. Kharkongor, M. Rajbangshi, B. Myrboh, Tetrahedron Lett. 52, 3228, (2011).

17. H. Mecadon, M.R. Rohman, M. Rajbangshi, B. Myrboh, Tetrahedron Lett. 52, 2523, (2011)

18. K. Kanagaraj, K.Pitchumani, Tetrahedron Lett.51, 3312, (2010).

19. A. Siddekha, A. Nizam, M. A. Pasha, Spectrochim. Acta A. 81, 431, (2011).

20. S.Kantevari, S. V. N. Vuppalapati, L. Nagarapu, Catal. Commun. 8, 1857, (2007).

21. (a) C. Noonan, L. Baragwanath, S. J. Connon, Tetrahedron Lett.49, 4003, (2008).(b) P. Jung, D.K. Nitsche, A. Demir, A.S. Siegert, P. Lingen, B. Baumann, M. Dünkelmann, P.M. Müller, J. Am. Chem. Soc. 124, 12084, (2002). (c) S. Orlandi, M. Caporale, M. Benaglia, R. Annunziata, Tetrahedron: Asymmetry 14, 3827, (2003). (d) J. Sheenan, D.H. Hunneman, J. Am. Chem. Soc.88, 3666, (1966). (e) J. Sheenan, T. Hara, J. Org. Chem.39, 1196, (1974).

22. (a) M. Lei, L. Ma, L.Hu, Monatsh. Chem.141, 1005, (2010).(b) M. Lei L. Ma, L. Hu, Synth. Commun.41, 199, (2011). (b) M. Lei, L. Ma, L. Hu, Synth.Commun.41, 3424, (2011). (c) M. Lei, L. Ma, L. Hu, Synth. Commun. 41, 2011, (1969). (d) S. Fatma, P.K. Singh, P. Ankit, Shireen, M. Singh, J. Singh, Tetrahedron Lett.54, 6732, (2013).

23. (a) J. T. Li, Y. Yin, M. X. Sun, Ultrason. Sonochem.17, 363, (2010).(b) T.S. Saleh, N.M.A. El-Rahman, Ultrason. Sonochem.16, 237, (2009).

24. R. Cella, H. A. Stefani, Tetrahedron65, 2619, (2009).

25. (a) R. S. Joshi, P. G. Mandhane, S. D. Diwakar, C. H. Gill, Ultrason. Sonochem.17, 298, (2010). (b) R. S. Joshi, P. G. Mandhane, P. V. Badadhe, C. H. Gill, Ultrason. Sonochem.18, 735, (2011).(c) S.K. Dabhade, R.O. Bora, M. Farooqui, C.H. Gill, Chin. Chem. Lett.20, 893, (2009). (d) D.R. Nagargoje, P.G. Mandhane, S. Shingote, P.V. Badadhe, C.H. Gill, Ultrason. Sonochem. 19, 94, (2012).

26. (a) P.G. Mandhane, R.S. Joshi, D.R. Nagargoje, C.H. Gill, Tetrahedron Lett.51, 3138, (2010). (b) P.G. Mandhane, R.S. Joshi, D.R. Nagargoje,
C.H. Gill, Chin. Chem. Lett. 22, 563, (2011). (c) P.V. Badadhe, A.V. Chate, D.G. Hingane, P.S. Mahajan, N.M. Chavhan, C.H. Gill, J. Korean Chem. Soc.55, 6, (2011). 